\title{
The Role of Regulatory T Cell in Nontypeable Haemophilus influenzae-Induced Acute Exacerbation of Chronic Obstructive Pulmonary Disease
}

\author{
Xuewa Guan, ${ }^{1}$ Yanjiao Lu, ${ }^{1}$ Guoqiang Wang, ${ }^{1}$ Peter Gibson $\left(i D,{ }^{2}\right.$ Fang Chen $\left(i D,{ }^{1}\right.$ Keyong Fang, \\ Ziyan Wang, ${ }^{1}$ Zhiqiang Pang, ${ }^{1}$ Yingqiao Guo, ${ }^{1}$ Junying Lu, ${ }^{1,3}$ Yuze Yuan, ${ }^{1}$ Nan Ran, \\ and Fang Wang $\mathbb{D}^{1}$
}

${ }^{1}$ Department of Pathogeny Biology, College of Basic Medical Sciences, Jilin University, Changchun 130021, China

${ }^{2}$ Department of Respiratory and Sleep Medicine, John Hunter Hospital, Newcastle, NSW, Australia

${ }^{3}$ Department of Intensive Care Unit, First Hospital of Jilin University, Changchun 130021, China

Correspondence should be addressed to Fang Wang; wf@jlu.edu.cn

Received 5 October 2017; Revised 8 January 2018; Accepted 6 February 2018; Published 13 March 2018

Academic Editor: Hwan-suck Chung

Copyright (C) 2018 Xuewa Guan et al. This is an open access article distributed under the Creative Commons Attribution License, which permits unrestricted use, distribution, and reproduction in any medium, provided the original work is properly cited.

\begin{abstract}
Chronic obstructive pulmonary disease (COPD) is associated with irreversible persistent airflow limitation and enhanced inflammation. The episodes of acute exacerbation (AECOPD) largely depend on the colonized pathogens such as nontypeable Haemophilus influenzae (NTHi), one of the most commonly isolated bacteria. Regulatory T cells (Tregs) are critical in controlling inflammatory immune responses and maintaining tolerance; however, their role in AECOPD is poorly understood. In this study, we hypothesized a regulatory role of Tregs, as NTHi participated in the progress of COPD. Immunological pathogenesis was investigated in a murine COPD model induced by cigarette smoke (CS). NTHi was administrated through intratracheal instillation for an acute exacerbation. Weight loss and lung function decline were observed in smoke-exposed mice. Mice in experimental groups exhibited serious inflammatory responses via histological and cytokine assessment. Expression levels of Tregs and Th17 cells with specific cytokines TGF- $\beta 1$ and IL-17 were detected to assess the balance of pro-/anti-inflammatory influence partially. Our findings suggested an anti-inflammatory activity of Tregs in CS-induced model. But this activity was suppressed after NTHi administration. Collectively, these data suggested that NTHi might play a necessary role in downregulating Foxp3 to impair the function of Tregs, helping development into AECOPD.
\end{abstract}

\section{Introduction}

Chronic obstructive pulmonary disease (COPD) has been considered as the fourth leading cause of death globally. It is characterized by progressive, persistent airflow limitation, usually associated with enhanced chronic inflammatory responses in the airways and the lung according to the Global Initiative for Chronic Obstructive Lung Disease. Cigarette smoke (CS), as the main cause of COPD, influences pulmonary environment and increases susceptibility to respiratory infections [1]. During the periods of exacerbation with intensified symptoms, pathogen infection has been considered being a central component. Repeated exacerbations and recruited inflammatory mediators [2] are believed to distort function of innate and adaptive immune responses, which might lead to an altered respiratory host defense and progressive airflow limitation, contributing to the progress of COPD [3].

Nontypeable Haemophilus influenzae (NTHi) is believed to be one of the primary pathogens causing AECOPD as it spreads down to the lower respiratory tract [4]. Colonized NTHi in the airway could impair ciliary function [5], enhance mucus expression [6], and provide opportunities for further infection. As the most frequently isolated agent from COPD patients [7], NTHi might aggravate the inflammatory responses generated by smoking, leading to a progressive airway obstruction, declined lung function, and remodeled pulmonary tissue. 
Regulatory $\mathrm{T}$ cells (Tregs), a subgroup of $\mathrm{CD} 4^{+} \mathrm{T}$ cells with a specific biomarker Foxp3, have been uncovered to play an important role in the development of COPD. In the airway of COPD, functions of Tregs exist as secreting anti-inflammatory factors and recruiting other anti-inflammatory cells $[8,9]$. Involved in the differentiation and expansion of Tregs, TGF- $\beta$ plays an immune-modulated role in maintaining immune homeostasis [10]. Elevated TGF- $\beta 1$ levels found in COPD patients were prone to an environment for Tregs differentiation [11]. In contrast with the proinflammatory pathway via Th17 cells, the role of Tregs in this pro- and anti-inflammatory balance has been widely studied despite controversial results [12]. Barcelo et al. found an upregulation of Tregs in smokers' BALF compared with never-smokers [13]. While another clinical research [14] indicated higher frequencies of Th17 cells with related IL-17A and IL-22 in serum and lower expression of Foxp3 in both moderate and severe COPD patients.

Compelling researches have been keen on the correlation between Tregs and bacteria. Some pathogen-specific Tregs are known to prevent pathological injury induced by infection. However, increased infection and persistence of pathogens might also take place due to the suppressing function of Tregs. Studies have shown enhanced host susceptibility to Listeria and Salmonella species when Treg expression was excessive [15]. In a chronic otitis media model, the percentage of Tregs increased after NTHi inoculation, while a depletion of Tregs could induce a $99.9 \%$ reduction of bacterial counts, indicating an infectious tolerance of Tregs to NTHi [16]. However, a decrease of Tregs-associated Foxp3 gene expression was observed in animals colonized with NTHi on day of life 3, indicating a downregulated effect of NTHi on Tregs [17]. Following these researches, the aim of this study is to continuously investigate the correlation between NTHi and Tregs in COPD murine model.

COPD might be caused by cigarette smoke. A combined colonization of NTHi could aggravate it into AECOPD. Based on the presence of a pro-/anti-inflammatory balance reflected by Th17/Treg cell response in COPD, we hypothesized that NTHi infection could impair the anti-inflammatory Treg balance and lead to AECOPD eventually.

\section{Materials and Methods}

2.1. Bacteria Incubation. NTHi (ATCC 49247) was purchased from Xiang Biological Technology Co. Ltd. (Shanghai, China). Bacteria were incubated on a chocolate agar for $18-24 \mathrm{~h}$ at $37^{\circ} \mathrm{C}$ in $5 \% \mathrm{CO}_{2}$. After a Gram staining identification, NTHi was continuously cultured for amplification and freeze preservation. Bacteria for administration was pelleted at $12,000 \times \mathrm{g}$ for $10 \mathrm{~min}$ and washed twice in PBS. A diluted concentration of $1 \times 10^{8} \mathrm{CFU} / \mathrm{ml}$ in PBS was required according to $\mathrm{OD}_{600}$ value.

2.2. Animals. Female 8-week BALB/c mice (Animal Center, Basic Medical Sciences College, Jilin University, SCXK(Ji)2015-0001) were randomly divided into 4 groups, including a normal control group (NC group), a cigarette smoke group (CS group), a NTHi group, and a group treated with a combination of cigarette smoke and NTHi (NTHi + CS group). All animals were fed under the same conditions and weighed once a week. Mice in the NC group were exposed to room air. The CS and NTHi + CS group mice were exposed to CS for 16 consecutive weeks. On the first day of the 17th week, NTHi was administrated to cause infection in the NTHi and NTHi + CS groups. 24 hours later, mice were deeply anaesthetized with $1 \%$ pentobarbital sodium on the basic of weight for subsequent experiments.

2.3. COPD Murine Model. Given that cigarette smoke is the major cause of COPD [18], we utilized a passive smoking method as the foundation of COPD inflammation model in mice, as many studies did $[19,20]$. Briefly, the CS and $\mathrm{NTHi}+\mathrm{CS}$ group mice were placed in a whole-body exposure sealed plastic box (chamber dimensions: $45 \mathrm{~cm} \times 31 \mathrm{~cm} \times 16 \mathrm{~cm}$, made in lab) with 8 ventholes $(d=5 \mathrm{~mm})$ on top of the box for ventilation, 1 venthole on the side for connection to the smoke source (standardized 3R4F research cigarettes, University of Kentucky, Lexington, $\mathrm{KY}$ ). An air pump was used for pumping smoke from lighted cigarettes into the box. Ventholes on top were blocked off while pumping. Two cigarette smokes were continuously inhaled into the sealed box each time to get a concentration of $300 \mathrm{mg} / \mathrm{m}^{3}$ total suspended particles, lasting for $10 \mathrm{~min}$. Then, mice got a rest for $10 \mathrm{~min}$ with the cover removed. The above steps were carried out 6 times (smoking exposure time: $1 \mathrm{~h}$ ) a day, 6 days per week, with a total duration of 16 weeks.

2.4. Treatment of NTHi. An intratracheal infection technique was used for administration of NTHi [21]. On the first day of the 17th week, mice in the NTHi and NTHi + CS groups were anaesthetized with pentobarbital sodium and vertically hung via their front teeth, in front of a cold light illuminator against the trachea. $50 \mu \mathrm{l}$ NTHi with a density of $1 \times 10^{8} \mathrm{CFU} / \mathrm{ml}$ was administrated by dripping into the mouse trachea to cause infection in the NTHi and $\mathrm{NTHi}+\mathrm{CS}$ groups. Same amount of PBS was administrated into the mice in other groups under the same conditions for control. $24 \mathrm{~h}$ later, mice were deeply anaesthetized for subsequent experiments.

2.5. Measurement of Animal Lung Function. Invasive lung function was investigated with anesthesia and tracheal instrumentation [22]. After being deeply anaesthetized with pentobarbital sodium, mice were fixed on panels for tracheal cannulation. The trachea was separated, and a cut was made in the upper trachea cartilaginous rings. A cannula was inserted into the trachea via the cut and fixed by operating line. Spirometer (Buxco, PFT Controller, DSI, USA) was utilized to test lung function [23]. After correct connection of the animal, pneumatic sensor and pressure sensor, a calm breath was recorded for a baseline value. Then, the parameters of lung volume, static and dynamic lung function including forced expiratory volume in $100 \mathrm{~ms}$ (FEV0.1), functional residual capacity (FRC), and airway resistance (RI), were measured automatically via the spirometer. 
2.6. H\&E Staining and Immunohistochemistry. After being extracted and washed in PBS, lung tissue from mice was fixed in formalin and embedded in paraffin sections via standard protocols. Hematoxylin and eosin staining was performed to assess histology. The mean linear intercept $(\mathrm{Lm})$ was calculated from the number of intercepts, the length of the line, and the number of times the line was placed on the sections $[24,25]$. Detections of Foxp3 and ROR $\gamma$ t protein expression were shown by immunohistochemistry through specific antibodies binding. Anti-Foxp3 and anti-ROR $\gamma \mathrm{t}$ antibodies were purchased from Abcam (United Kingdom). Motic Images Advanced 3.2 was applied to analyze the intensity of protein expression.

2.7. Western Blot. Lung tissue from mice was ground into homogenates at the condition of $4^{\circ} \mathrm{C}$ for protein detection [26]. Total protein was extracted via a Total Protein Extraction Kit (Invent Biotechnologies Inc., USA) according to the manufacturer's protocol. Enhanced BCA Protein Assay Kit (Beyotime, Jiangsu, China) was used for concentration detection. Protein samples were then separated by SDSPAGE gel electrophoresis on $12 \%$ glycine-based gels and transferred to nitrocellulose membranes (Millipore Corp., Billerica, MA, USA). Membranes were blocked in 5\% $(w / v)$ skimmed milk for $2 \mathrm{~h}$ and incubated with antibodies in $5 \%$ $(w / v)$ BSA overnight at $4^{\circ} \mathrm{C}$. Anti-Foxp3 antibody, antiROR $\gamma t$ antibody, and anti-GAPDH antibody were purchased from Abcam (United Kingdom). Membranes were then incubated with secondary HRP-labeled antibody (SigmaAldrich, St. Louis, MO, USA) in 5\% (w/v) BSA for $1 \mathrm{~h}$. Afterwards, enhanced chemiluminescence (Beyotime, Jiangsu, China) was developed on membranes. The intensity of bands was quantified by densitometry using ImageJ software (National Institutes of Health, Bethesda, MD, USA).

2.8. ELISA. Blood was obtained and centrifuged at a speed of $3000 \mathrm{rpm}$ for $10 \mathrm{~min}$ at $4^{\circ} \mathrm{C}$. Serum was collected for assessing the levels of inflammatory cytokines TGF- $\beta$ and IL-17 by Mouse ELISA Kit (RayBiotech, USA). IL-1 $\beta$, IL-6, and TNF- $\alpha$ were quantified in lung homogenates using commercial ELISA kits (eBiosciences).

2.9. RNA Isolation and RT-qPCR. The lungs were collected under aseptic conditions and ground into homogenates at the condition of $4^{\circ} \mathrm{C}$. After being isolated from a RNeasy mini Kit (Qiagen, USA), total RNA was reverse transcribed into cDNA using PrimeScript TM RT Reagent (Takara, Japan). Then, qPCR was presented with Roche FastStart Universal SYBR Green ROX (Roche, Sweden) to determine mRNA expression of Foxp3, ROR $\gamma \mathrm{t}$, and $\beta$-actin (house-keeping gene). All primers were designed and purchased from Kumei (Jilin, China). The $\Delta \Delta$ Ct method was performed to show the relative expression level of Foxp3 and ROR $\gamma \mathrm{t}$ mRNA. Primer sequences of mouse Foxp3, ROR $\gamma$ t, and $\beta$-actin are shown as follows: mouse Foxp3 forward primer, $5^{\prime}$-ATCCTACCCACTGCTGGCAAAT- $3^{\prime}$; mouse Foxp3 reverse primer, $5^{\prime}$-AGAGACTGCACCACTTCTC TCT-3'; mouse ROR $\gamma \mathrm{t}$ forward primer, $5^{\prime}$-GACGGCC AACTTACTCTTGGA-3'; mouse ROR $\gamma$ t reverse primer,

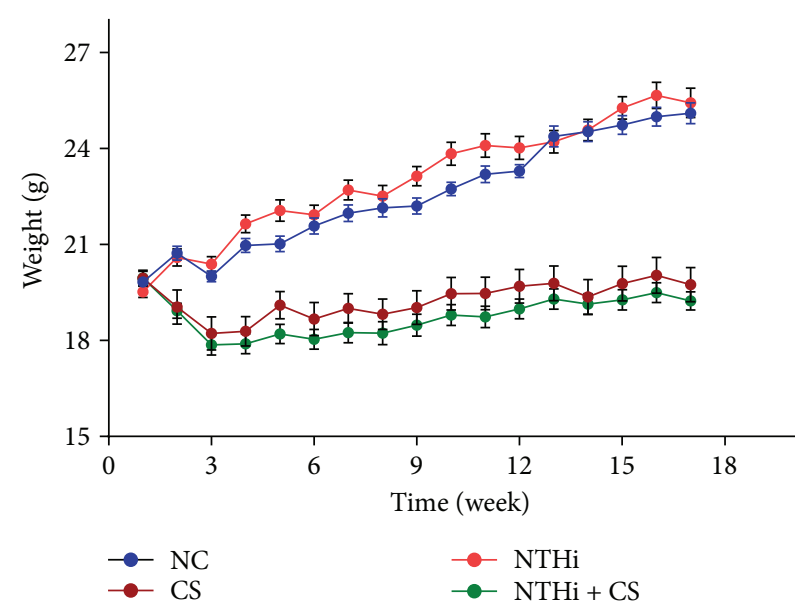

FIgURE 1: Weight change on mice during a 17 -week experiment. Body weight was measured once a week, fasting $12 \mathrm{~h}$ before each weighing. $n=15$ in each group. Data was expressed as mean \pm SD.

$5^{\prime}$-CTCGGAAGGACTTGCAGACAT- $3^{\prime}$; mouse $\beta$-actin forward primer, $5^{\prime}$-GATCAAGATCATTGCTCCTCCTG-3'; and mouse $\beta$-actin reverse primer, $5^{\prime}$-AGGGTGTAAAA CGCAGCTCA-3'.

2.10. Statistical Analysis. GraphPad Prism 6.0 was used for statistical analysis. The results are expressed as mean $\pm \mathrm{SD}$. One-way ANOVA-LSD was used to compare among groups. $p$ value $<0.05$ was considered statistically significant, and data was tested at level $\alpha=0.05$.

\section{Results}

3.1. Cigarette Smoke Caused a Weight Loss in Mice. We first examined a direct influence of CS and NTHi on mouse body weight. Mice were weighed once a week. As shown in Figure 1, mice in the CS and CS + NTHi groups had a significant reduced weight compared with the NC. Since mice were sacrificed $24 \mathrm{~h}$ after challenged with NTHi, there was no significant change between the NTHi and NC groups. These helped us to infer that CS might cause a weight loss in mice.

3.2. Cigarette Smoke with NTH Impaired Lung Function in Mice. Spirometry was utilized to assess lung function in this murine COPD model. Indexes as FEV0.1, FRC, and RI showed great changes in experimental groups in Figure 2. CS decreased FEV0.1 significantly $(p<0.001)$, while increased FRC $(p<0.001)$ and RI $(p<0.05)$ compared to NC. Consistent with these observations, the results of dynamic lung function indicated a decrease of lung function in all experimental groups especially in the NTHi + CS group, with smaller lung volume and lower airflow compared to NC notably at the end of each inspiration $(p<0.001)$ (Figures 2(d) and 2(e)). These results demonstrated a significant impact of CS and NTHi on lung function.

3.3. Morphology Impairment on Lung Tissue in the CS and NTHi Groups. Changes in pulmonary morphology, integrity of epithelial cells, and infiltration of inflammatory cells were 


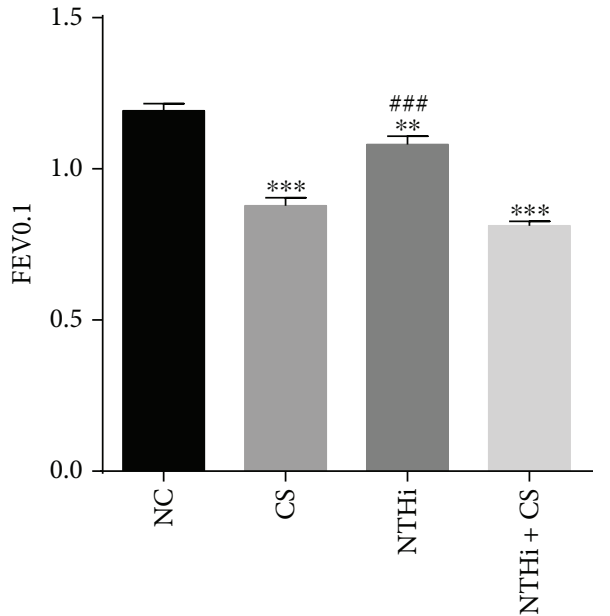

(a)

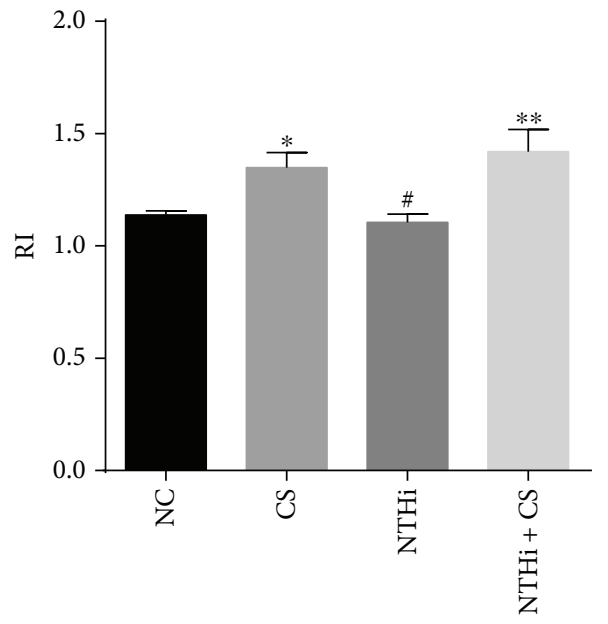

(c)

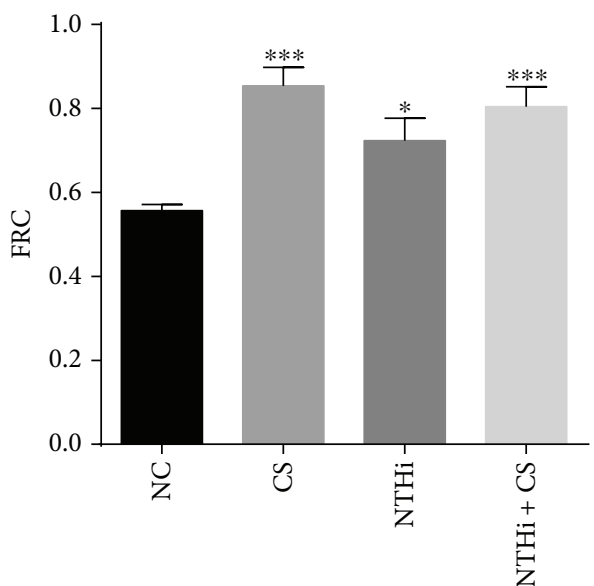

(b)

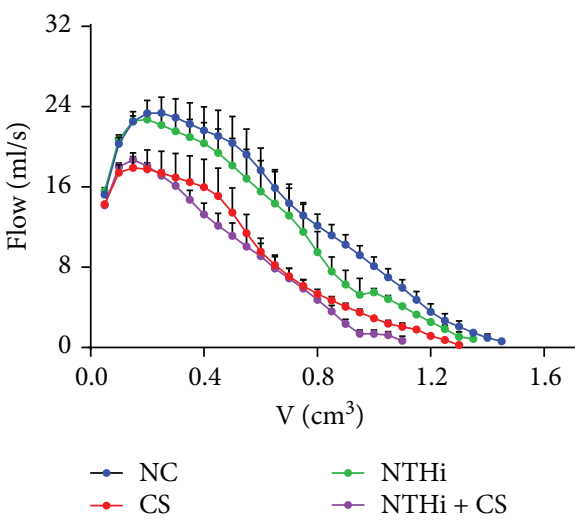

(d)

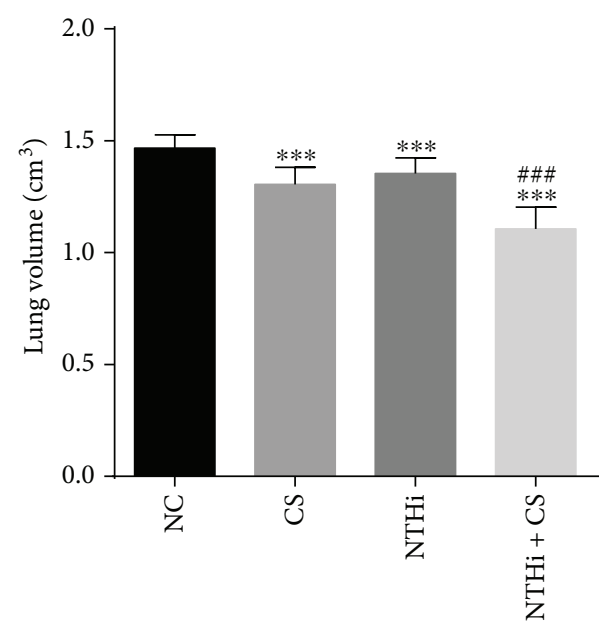

(e)

FIGURE 2: Lung function testing on mice. Invasive lung function was investigated with anesthesia and tracheal instrumentation. FEV0.1 (forced expiratory volume in $100 \mathrm{~ms}$ ), FRC (functional residual capacity), and RI (airway resistance) in the NC, CS, NTHi, and NTHi + CS groups were shown in (a), (b), and (c), respectively. (d) Dynamic lung function, with $x$-coordinate representing lung volume and $y$-coordinate representing airflow. (e) Lung volume at the end of each inspiration. $n=5-7$ in each group; each test was repeated three times. Data was expressed as mean \pm SD. Analysis of differences among groups was conducted with one-way ANOVA-LSD. ${ }^{*} p<0.05$, ${ }^{* *} p<0.01$, and ${ }^{* * *} p<0.001$ versus NC; ${ }^{\#} p<0.05$ and ${ }^{\# \# \#} p<0.001$ versus CS. 
shown in Figure 3. In the NC group, there was no evident pathological change and no appreciable inflammatory cell infiltration, with integrated bronchial epithelial tissue structure (Figure 3(a)). Lung and bronchial epithelial tissue in smoke-exposed mice showed mild loss and drop. An inflammatory cell infiltration was observed in alveolar space (Figure 3(b)). Lung tissue sections presented granulocyte infiltration, enlarged airspaces, and thicker alveolar septum in the NTHi group (Figure 3(c)). The pathological damage in the $\mathrm{NTHi}+\mathrm{CS}$ group was even severer, with greater expansion of the alveolar spaces. A large amount of accumulated inflammatory cells could be observed, as shown in Figure 3(d). These results revealed that CS and NTHi could both cause inflammatory and histological change in respiratory to some extent, and a combination of both agents could cause a severer damage. The mean linear intercept $(\mathrm{Lm})$ was significantly higher by CS exposure $(p<0.001)$ and NTHi administration $(p<0.001)$ compared to NC, especially in the CS + NTHi group $(p<0.001)$.

\subsection{Cigarette Smoke Together with NTHi Induced High Levels} of Inflammatory Cytokines in the Lung. To assess the inflammatory responses in the CS and NTHi groups, ELISA was used to detect inflammatory cytokines IL-1 $\beta$, IL- 6 , and TNF- $\alpha$ in lung homogenates as shown in Figures 4(a), 4(b), and 4 (c). Besides, TGF- $\beta 1$ and IL-17 were detected in serum. Compared to the NC group, mice in experimental groups showed increased inflammatory cytokine expression in the lung, especially when challenged with NTHi $(p<0.001)$. The circulating TGF- $\beta 1$ and IL-17 (Figures 4(d) and 4(e)) in serum were presented at significantly higher concentration in the CS and NTHi + CS groups than in the NC $(p<0.05$ and $p<0.01)$. However, there was an opposite trend in the NTHi group, where an increase of IL-17 level $(p<0.001)$ and decrease of TGF- $\beta 1$ level $(p<0.001)$ were observed compared to the NC. These results helped to suggest an aggravating inflammation when NTHi and CS were combined and an existent role of Th17 and Tregs in this progress via the expression of TGF- $\beta 1$ and IL-17.

3.5. Effects of Cigarette Smoke and NTHi on Foxp 3 and ROR $\gamma t$ Protein Expression in the Lung. To partially study the expressions of Tregs and Th17 cells, Foxp3 and ROR $\gamma \mathrm{t}$, as biomarkers of these two subsets of $\mathrm{CD}^{+}{ }^{+} \mathrm{T}$ cells, were detected at protein level, respectively. Immunohistochemical on lung tissue sections in Figure 5 demonstrated a similar expression of Foxp3 in each group. Compared to the NC group, the expression of ROR $\gamma$ t increased significantly in experimental groups $(p<0.001, p<0.001$, and $p<0.001)$, especially in smoke-exposed mice when challenged with NTHi.

Western blot analysis was further investigated on protein expression of Foxp3 and ROR $\gamma \mathrm{t}$ (Figure 6). In agreement with immunohistochemistry results, the level of Foxp3 was low without significant differences between each group. While ROR $\gamma$ t showed a great increase in the CS and NTHi groups $(p<0.05)$, with the highest expression in the $\mathrm{NTHi}+\mathrm{CS}$ group $(p<0.01)$. These results helped us to infer that CS together with NTHi could stimulate the expression of ROR $\gamma$ t significantly in the lung at protein level. Similar expression levels of Foxp3 across the experimental groups suggested that little concentration of this protein was detected in our study, which was confirmed by quantitative histologic analysis.

3.6. Effects of Cigarette Smoke and NTHi on Foxp3 and ROR $\gamma t$ at Gene Level in the Lung. Relative expression of Foxp3 and ROR $\gamma \mathrm{t}$ at mRNA level was assessed via real-time PCR and reported as $2^{-\Delta \Delta C t}$ manner (Figure 7). Compared to NC, mRNA expression of Foxp3 in the lung increased in the CS and NTHi groups but decreased in the NTHi + CS group $(p<0.05)$. ROR $\gamma$ t expression increased significantly in experimental groups, $(p<0.05, p<0.001$, and $p<0.001)$, with the largest increase in the NTHi + CS group. Based on these results, we could infer a strong effect of Th17 cells in the lung and an attenuated function of Tregs when CS and NTHi were combined, due to the decreased expression of Foxp3.

\section{Discussion}

In this study, we have established a successful moderate COPD murine model with cigarette smoke followed by NTHi administration to investigate the inflammatory responses on the pro-/anti-inflammatory balance in COPD, reflected by Th17/Treg cell responses. CS together with NTHi worsened lung functions and inflammatory responses in mice. As a single factor, NTHi did not have too much impact on lung function, but a relative decrease of FEV0.1 and a significant increase of RI could be observed after smoking exposure and NTHi administration. It was more accurate to reflect the various airflow as lung volume changed in a dynamic lung function curve, indicating an aggravated lung function when NTHi and CS were combined, with smaller lung volume and lower airflow. The impaired lung function could probably be explained through the pathological change. The increase in FRC suggested a dynamic pulmonary hyperinflation occurring after CS stimulation, while the increase in resistance might be due to the damage of respiratory tissue, as other researchers have demonstrated $[27,28]$. The thicker alveolar septae and larger expanded alveolar spaces revealed in histopathology not just weakened the lung elastic but indicated an inflammation caused by CS and NTHi, which are consistent with clinical COPD pathological features. Therefore, our model partially imitated the histopathology and lung function changes existed in COPD.

Microbiome has been widely studied and is believed to be a vital exacerbation risk in COPD patients [29]. In this study, based on the discoveries that NTHi was the most frequently isolated agent in COPD patient [7] and an important cause of exacerbations of COPD [30], we superimposed this bacterial exposure in a murine COPD model induced by CS to investigate the behavior of Tregs in inflammatory and immune responses. Consistent with our results, Ganesan et al. [31] also reported the role of NTHi in the progression of COPD. Increased goblet cells and mucin gene expression occurred during the development of lung inflammation. However, this did not happen with all pathogens, since some bacteria could attenuate the immune pathological injury in 


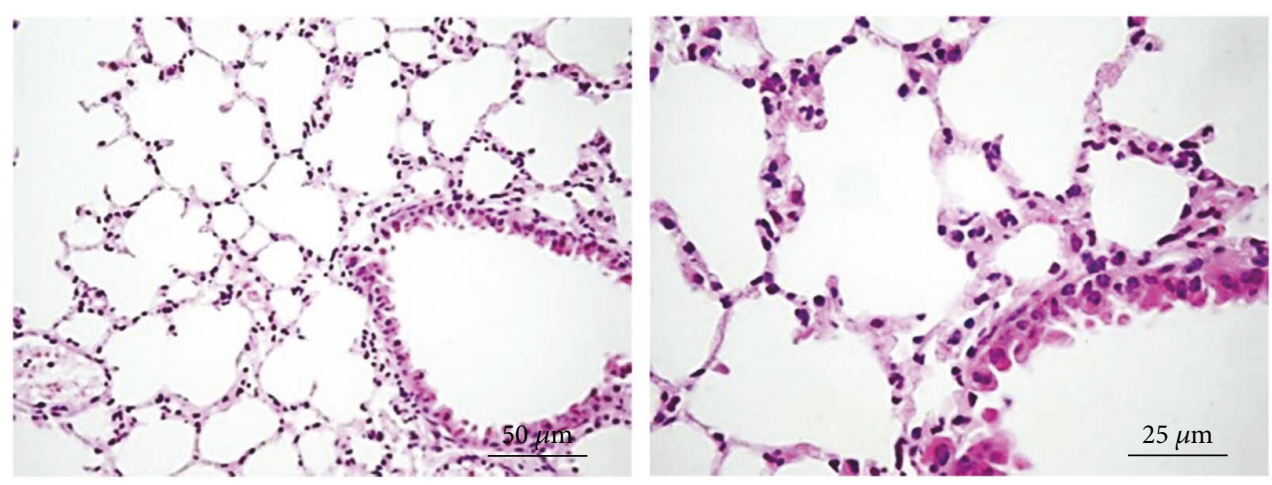

(a)
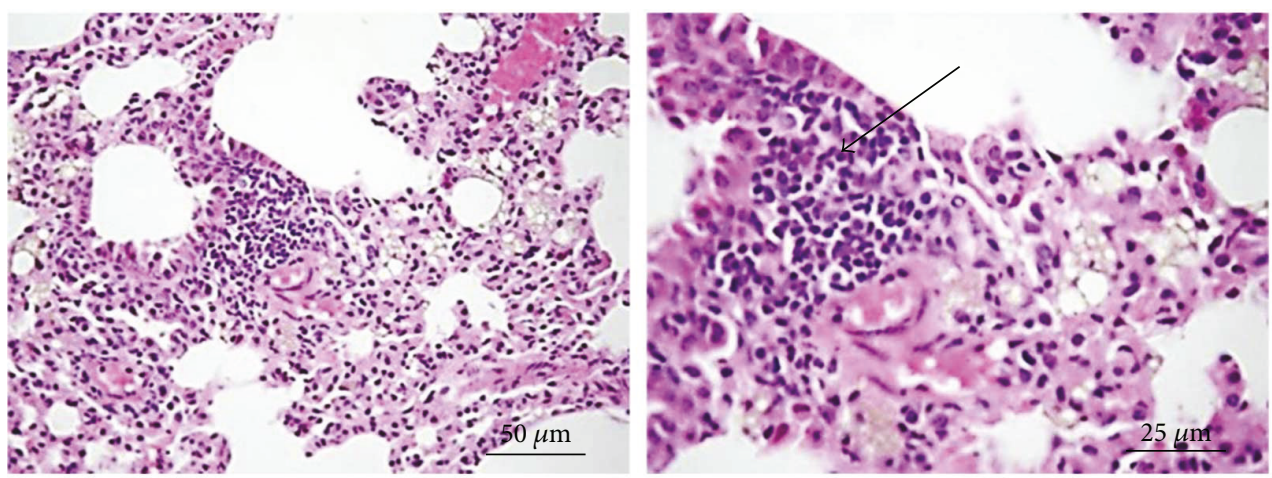

(b)

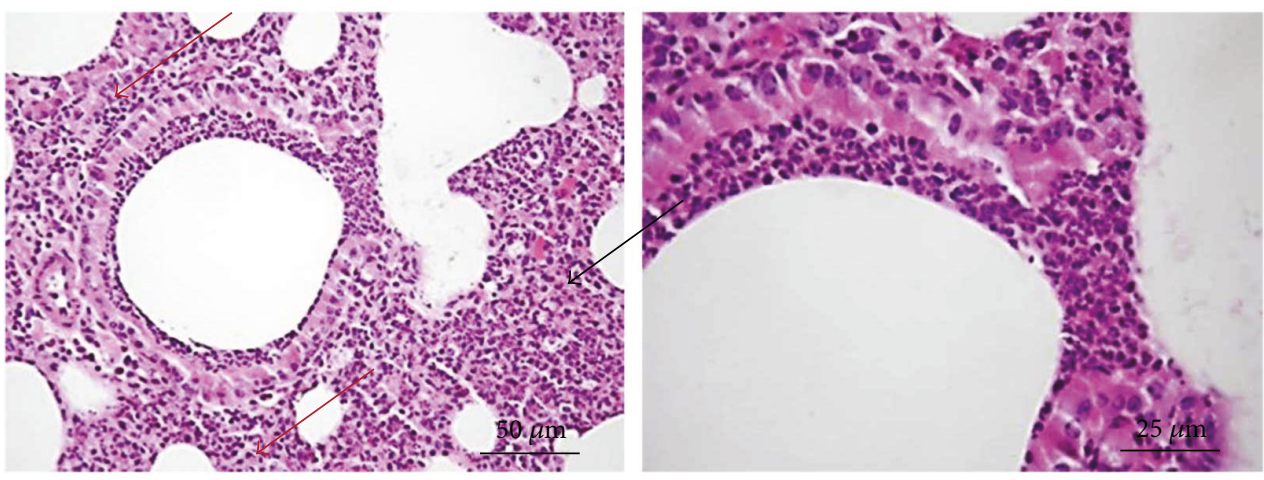

(c)

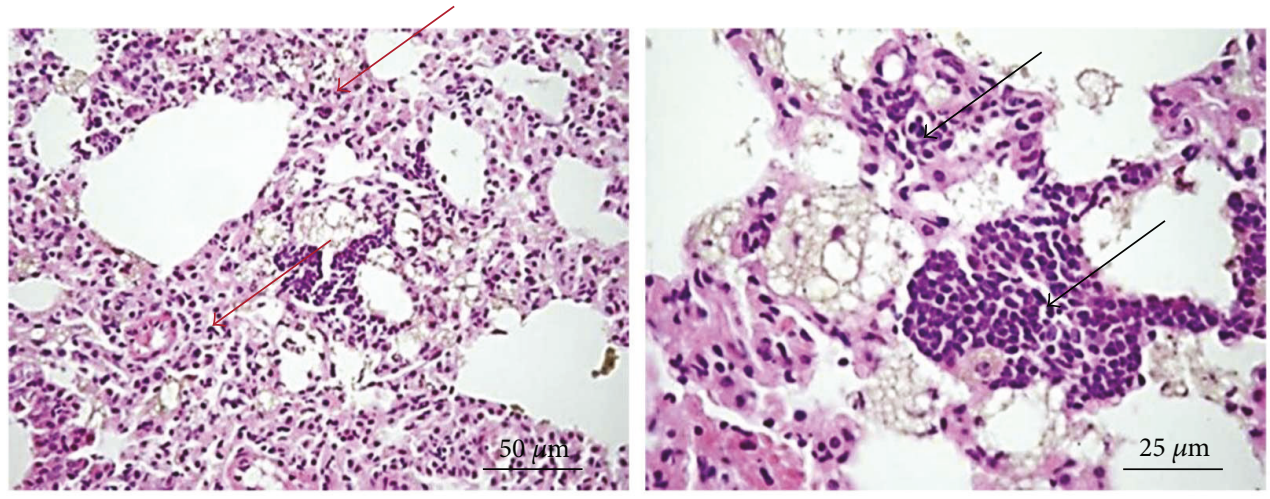

(d)

Figure 3: Continued. 


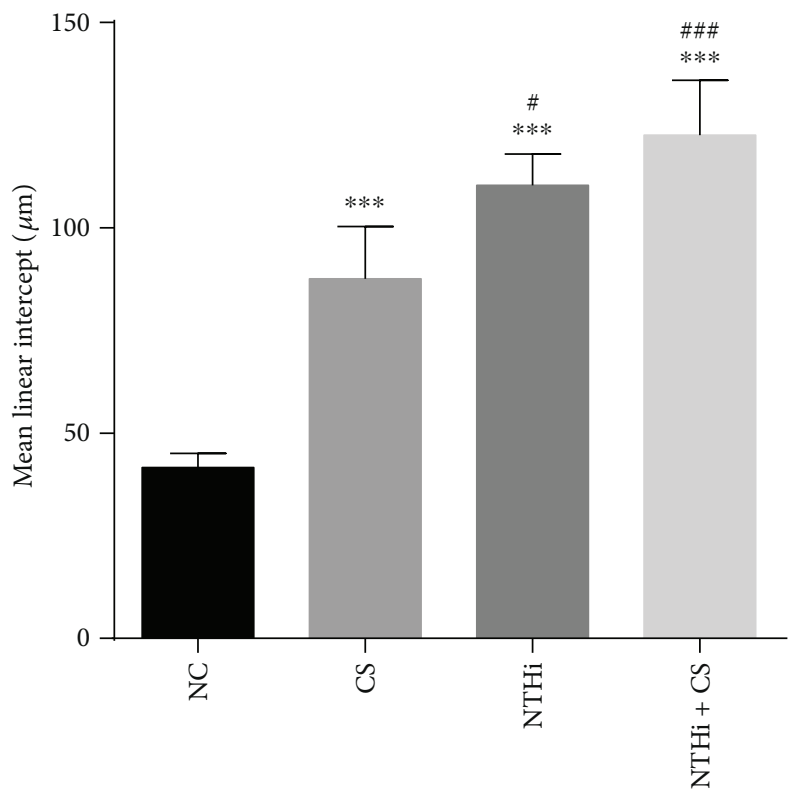

(e)

FIGURE 3: H\&E staining of lung tissue in mice. (a), (b), (c), and (d) represent lung tissue sections from the NC, CS, NTHi, and NTHi + CS groups, respectively (left: 200×; right: 400×). Black arrows in (b), (c), and (d) represented the infiltrating inflammatory cells. Red arrows represented thicker alveolar septum. (e) The mean linear intercept. Lm was calculated from the number of intercepts, the length of the line, and the number of times the line was placed on the sections. $n=3-4$ in each group. Data was expressed as mean \pm SD. Analysis of differences among groups was conducted with one-way ANOVA-LSD. ${ }^{* * *} p<0.001$ versus NC; ${ }^{\#} p<0.05$ and $\# \#$ \# $<0.001$ versus CS.

lung inflammation. Inactivated Klebsiella has been recently studied in both cigarette smoke-induced lung inflammation and allergic airway disease. Reductions in BAL inflammatory cytokines and systemic immune activation happened after inactivated Klebsiella administration, indicating a novel strategy to alter COPD pathological process and treat allergic airway disease [32, 33]. Streptococcus pneumoniae infection could also suppress allergic response in allergic airway disease by inducing Tregs [34, 35]. Lactobacillus rahmnosus and Bifidobacterium breve were believed to have anti-inflammatory effects in CS-induced COPD [36]. This dialectical role of pathogen infections on inflammation provided us a new field for further investigation on the impact of bacteria in respiratory disease.

Adaptive immune responses mediated by $\mathrm{T}$ cells play a critical role in the chronic persistent inflammation in COPD. Tregs and Th17 cells are two crucial subsets of $\mathrm{CD} 4^{+} \mathrm{T}$ cells that regulate inflammatory responses. Tregs have an active role in inhibiting immune responses and attenuating pulmonary inflammation $[37,38]$, while Th17 cells produce proinflammatory cytokines, mediating host defensive mechanisms against infection $[39,40]$. TGF- $\beta$ has been considered as an essential regulator in the generation and differentiation of Tregs converted from peripheral naive $\mathrm{CD} 4^{+} \mathrm{T}$ cells [41], also being protective in COPD. Zhang et al. [42] utilized a competitive receptor antagonist for TGF- $\beta$ type I receptors to indicate that impaired TGF- $\beta$ signaling might generate an imbalance of Th17/Treg ratio in the peripheral blood of smokers, suggesting a potential factor for COPD development. IL-17, as an important mediator in promoting tissue inflammation, could upregulate proinflammatory cytokines and chemokines [43]. Our results have shown a higher level of Foxp 3 and TGF- $\beta 1$ in the CS-induced COPD model, suggesting an increase of Tregs with a function of attenuating inflammation. However, aggravated inflammatory responses in the lung indicated that the immunosuppressive effect of Tregs was not capable of inflammatory inhibition. Consistent with our results, a clinical study on the Treg/IL-17 ratio in COPD demonstrated an increase of both proinflammatory and anti-inflammatory responses in patients with COPD, dominated by proinflammatory responses, indicating an insufficient of Tregs [44].

In this work, according to the varied expression of Foxp3 and TGF- $\beta 1$ in the CS-NTHi stimulated murine model, we firstly found a downregulatory effect of NTHi on Tregs. TGF- $\beta 1$, released from Tregs, dendritic cells, and macrophages, is traditionally thought to be an anti-inflammatory mediator. A dual function of TGF- $\beta 1$ has been discovered, based on the existence of IL- 6 . When IL- 6 is absent, TGF- $\beta 1$ is capable of inducing Treg cell development, while in the presence of IL-6, TGF- $\beta 1$ induces Th17 cells $[12,45,46]$. In our current study, observations of depressed Foxp3 mRNA expression and enhanced TGF- $\beta 1$ level in the CS + NTHi group could be probably due to the increase of IL-6, switching Tregs into a Th17 response in the presence of chronic infection. However, this hypothesis needs our further investigation. Overall, Tregs were generally differentiated for an attenuating inflammatory effect via TGF- $\beta 1$ in stable COPD against the Th17 proinflammatory effect, keeping an inflammation balance. However, after NTHi infection, Tregs were 


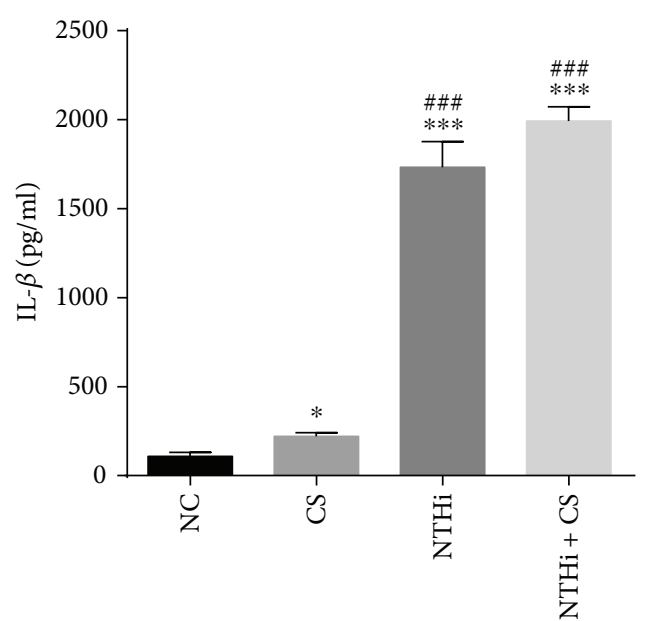

(a)

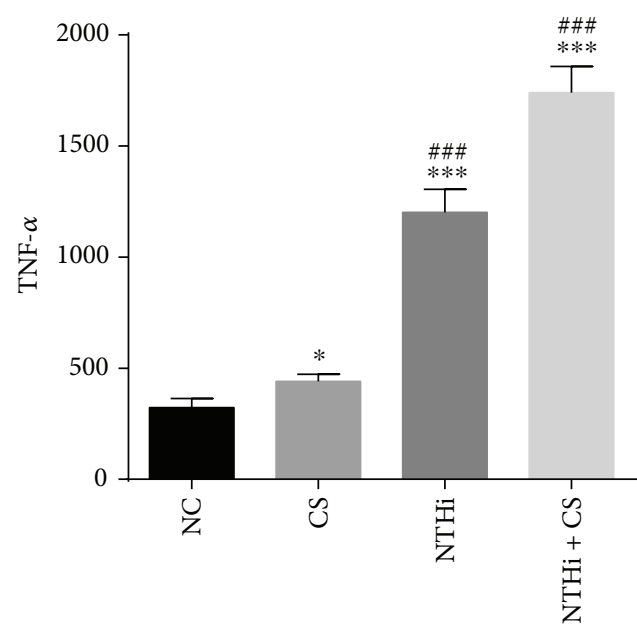

(c)

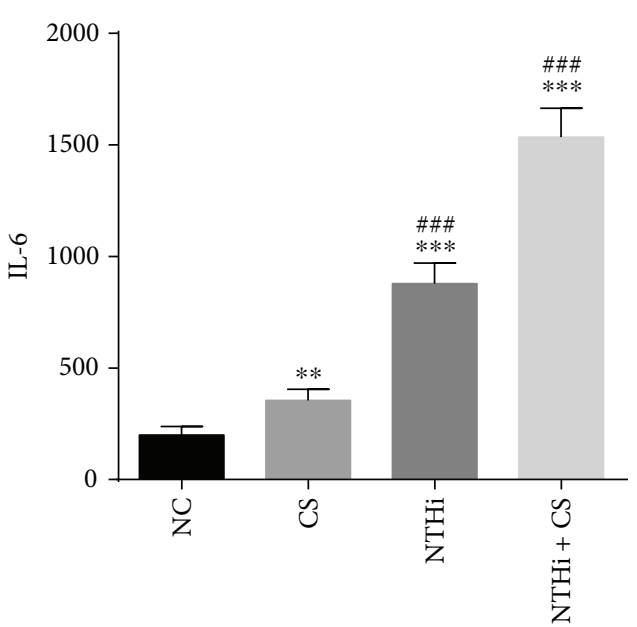

(b)

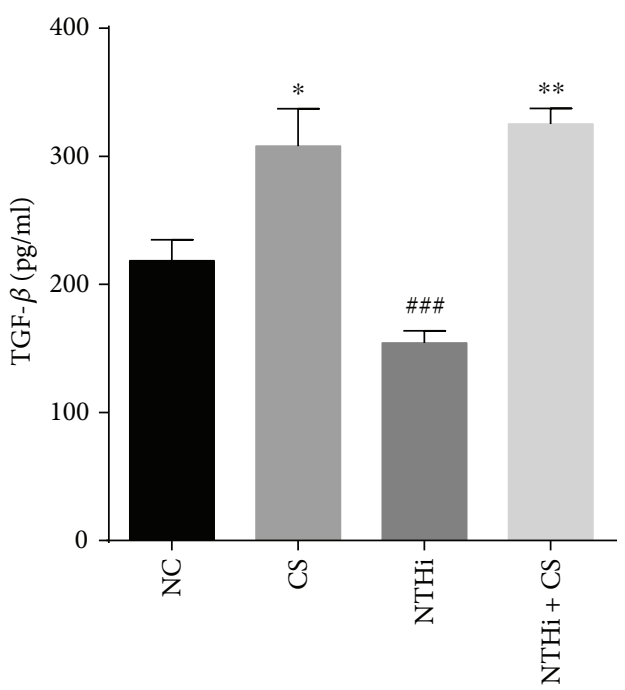

(d)

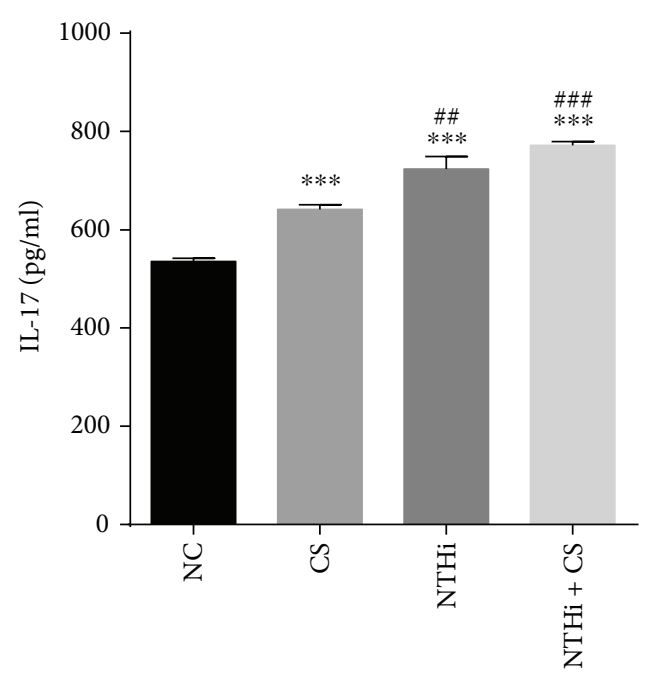

(e)

FiguRE 4: Expressions of inflammatory cytokines. IL-1 $\beta$, IL-6, and TNF- $\alpha$ were detected in lung homogenates (a, b, and c). Serum levels of TGF- $\beta 1$ and IL-17 in the four groups were presented in (d, e). $n=5-7$ in each group; each test was repeated three times. Data was expressed as mean \pm SD. Analysis of differences among groups was conducted with one-way ANOVA-LSD. ${ }^{*} p<0.05,{ }^{* *} p<0.01$, and ${ }^{* * *} p<0.001$ versus NC; ${ }^{\# \#} p<0.01$ and ${ }^{\# \# \#} p<0.001$ versus CS. 


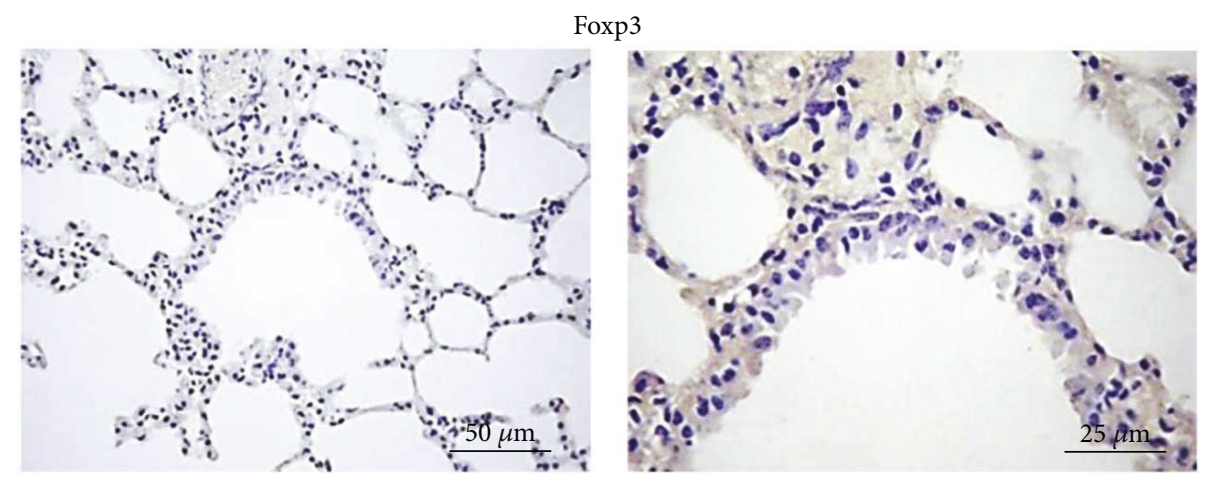

(a)

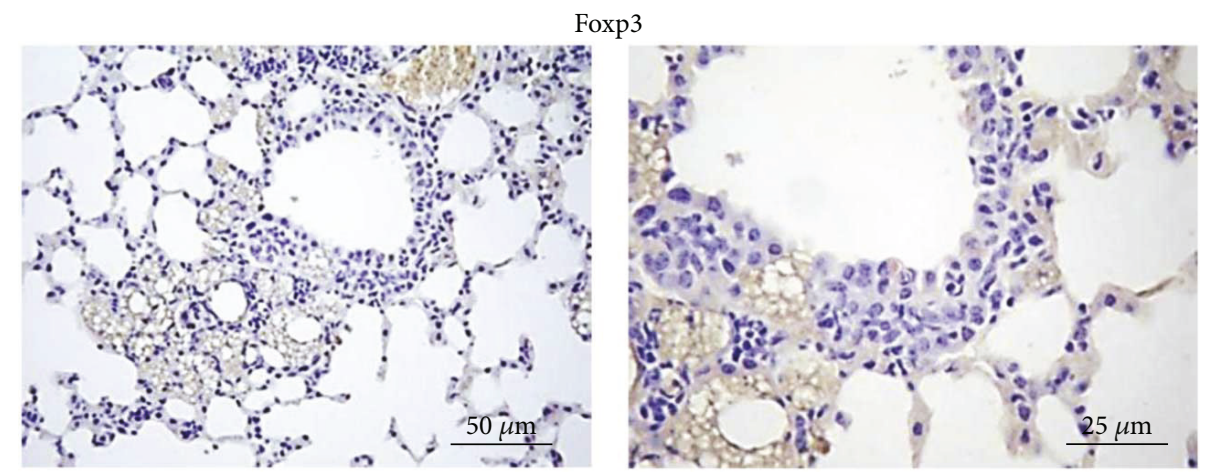

(b)
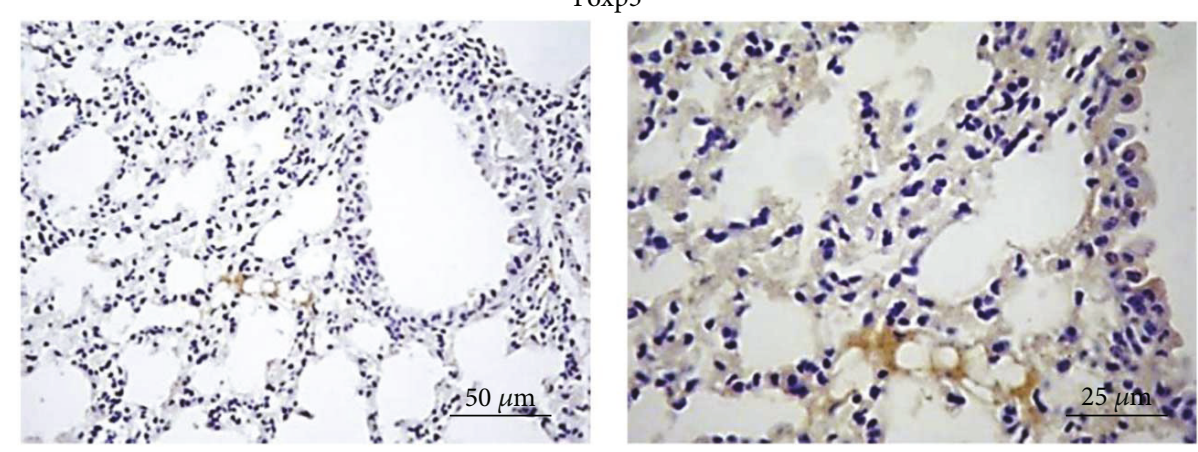

(c)

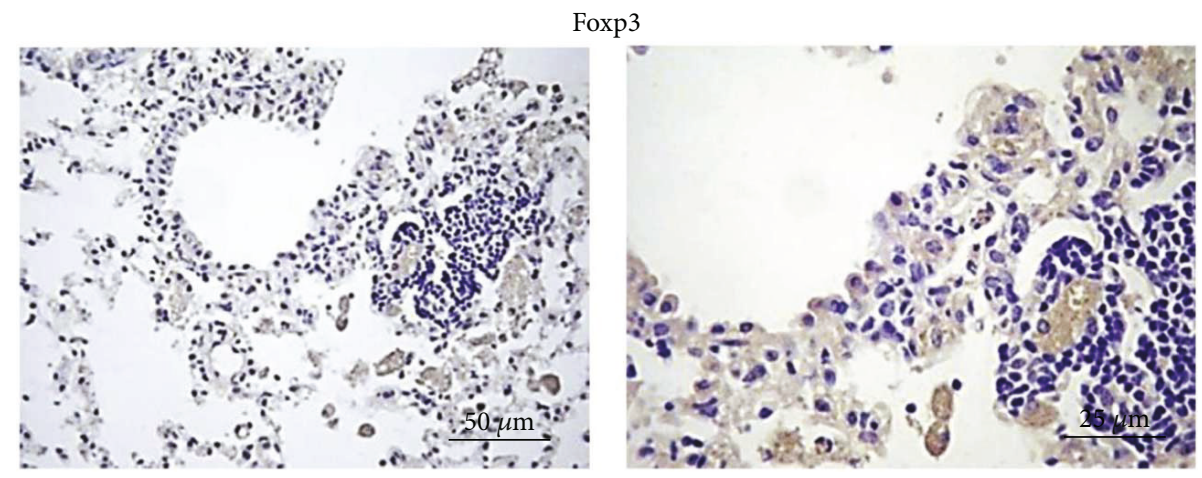

(d)

Figure 5: Continued. 


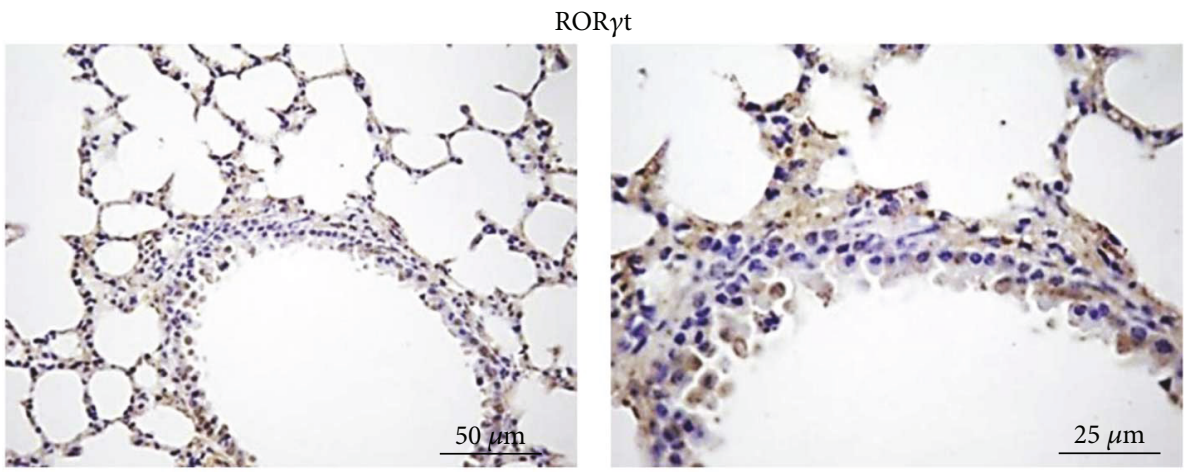

(e)
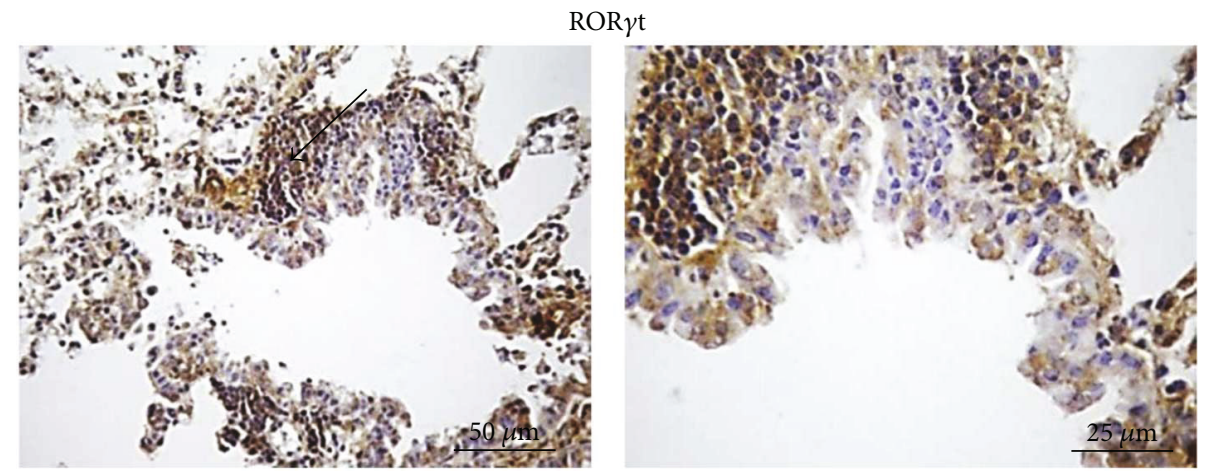

(f)

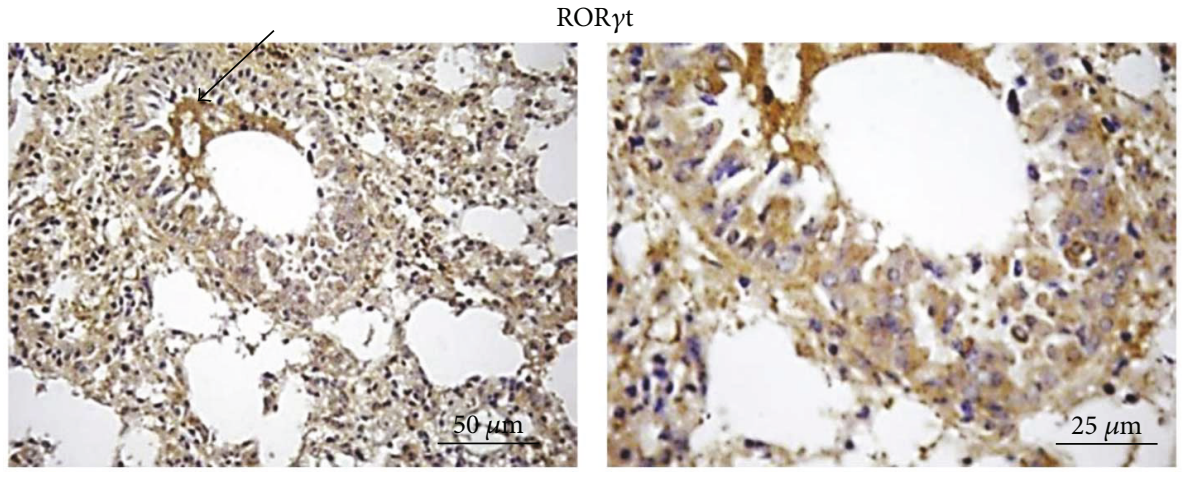

(g)

ROR $\gamma \mathrm{t}$

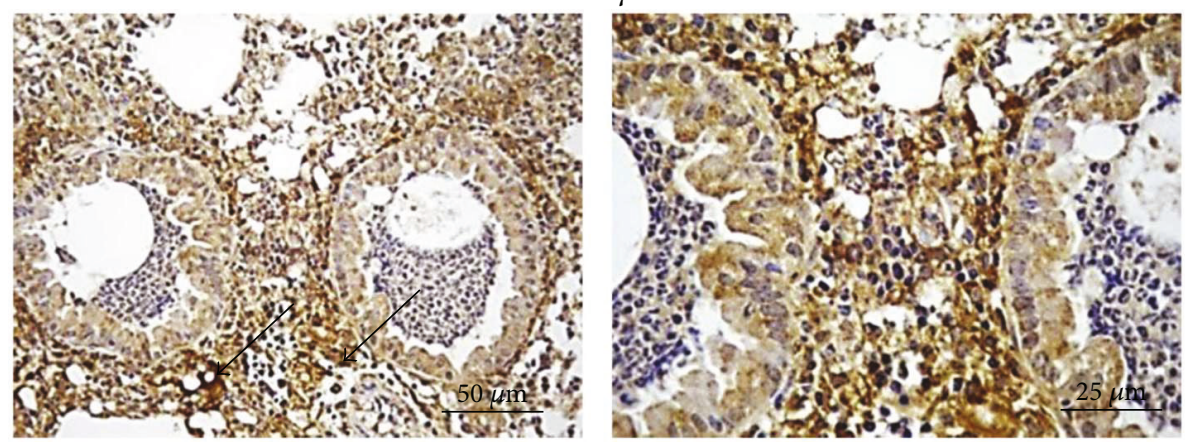

(h)

Figure 5: Continued. 


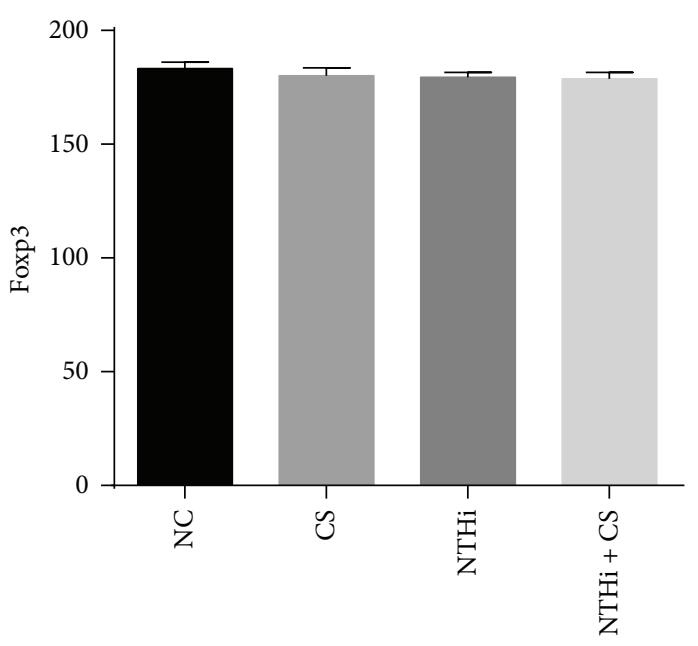

(i)

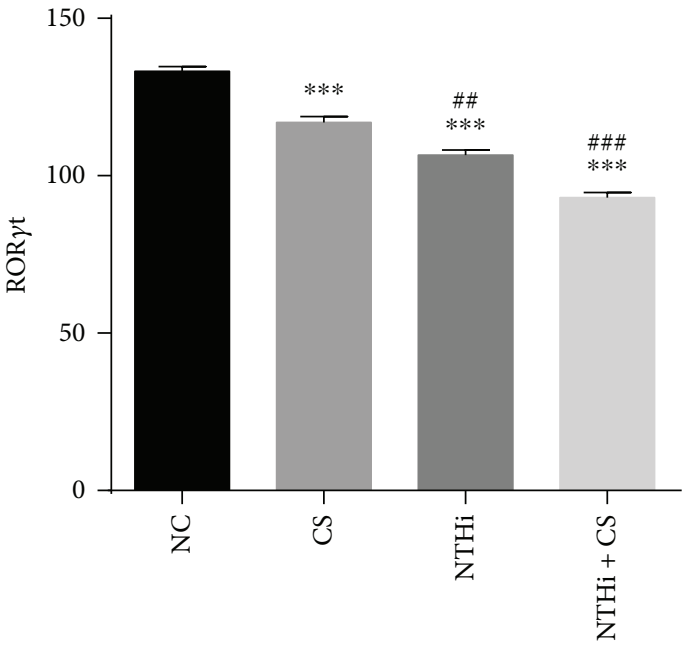

(j)

FIgURE 5: Immunohistochemical detection of Foxp3 and ROR $\gamma \mathrm{t}$. Lung tissue sections were immunostained with antibodies to Foxp3 and ROR $\gamma$ t. Color shade in $(\mathrm{a}-\mathrm{h})$ indicated the intensity of protein expression. Black arrows in ( $\mathrm{f}, \mathrm{g}$, and $\mathrm{h})$ represented high level of ROR $\gamma \mathrm{t}$ expression. Mean grey level of each section was analyzed via Motic Images Advanced 3.2, shown in (i and j). Higher grey level value meant lower positive expression. $n=4$ in each group. Data was expressed as mean \pm SD. Analysis of differences among groups was conducted with one-way ANOVA-LSD. ${ }^{* * *} p<0.001$ versus NC; ${ }^{\# \#} p<0.01$ and ${ }^{\# \# \#} p<0.001$ versus CS.

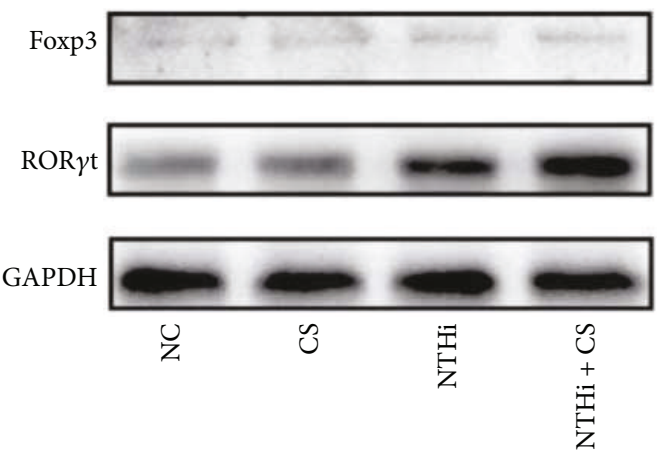

(a)

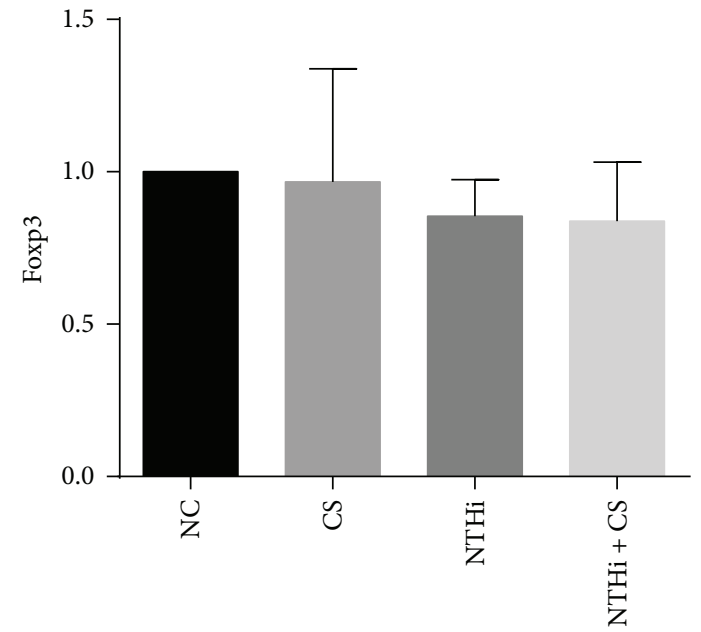

(b)

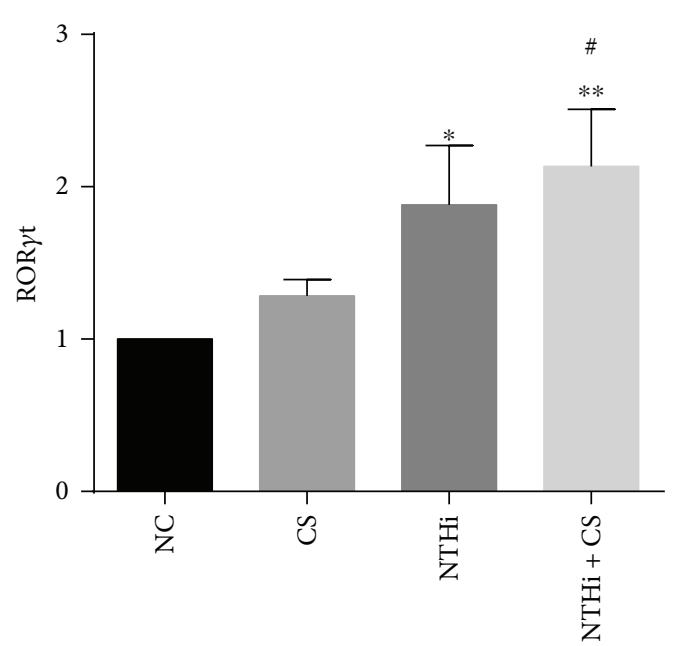

(c)

FIgURE 6: Foxp3 and ROR $\gamma$ t expressions in lung tissue via Western blot. Band intensity was quantified by densitometry using ImageJ software (National Institutes of Health, Bethesda, MD, USA). $n=3$ in each group. Data was expressed as mean \pm SD. Analysis of differences among groups was conducted with one-way ANOVA-LSD. ${ }^{*} p<0.05$ and ${ }^{* *} p<0.01$ versus NC; ${ }^{*} p<0.05$ versus CS. 


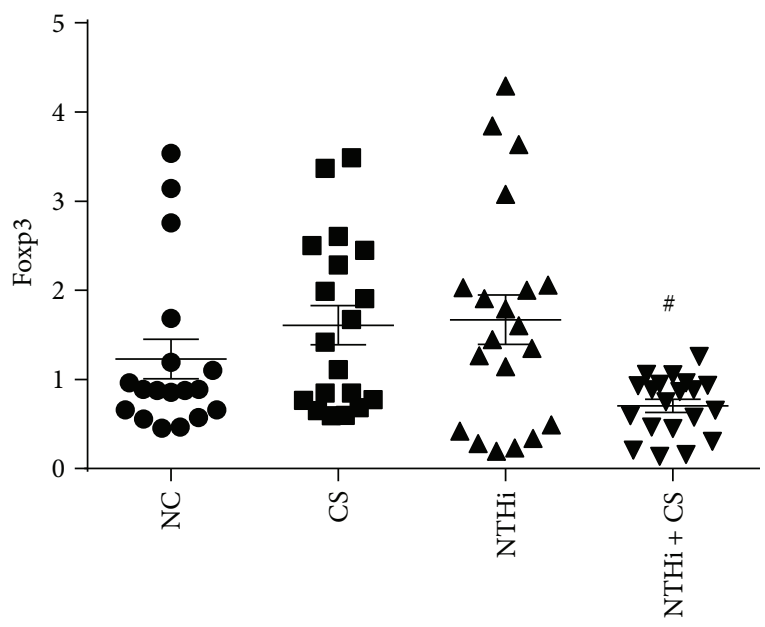

(a)

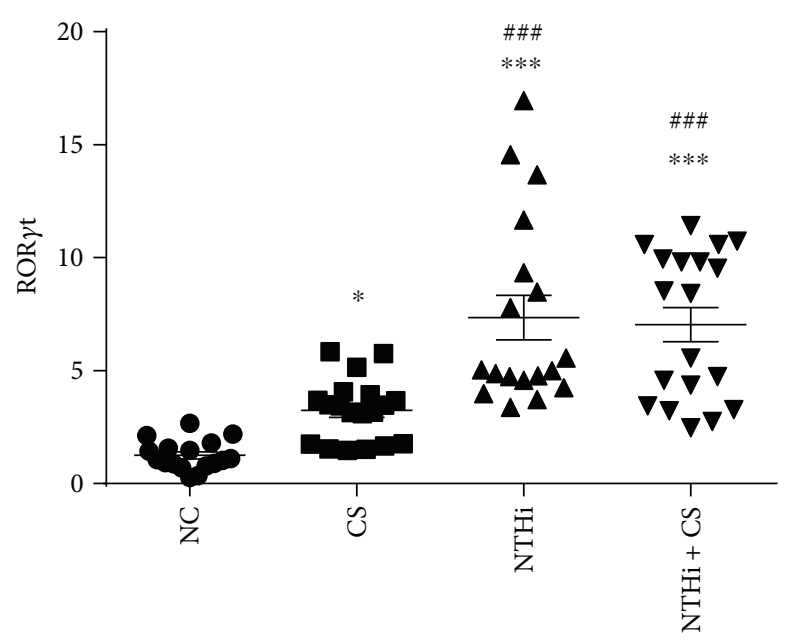

(b)

FIGURE 7: Gene expressions of Foxp3 and ROR $\gamma$ t in lung tissue. Relative mRNA expressions were assessed by qPCR and analyzed using $2^{-\Delta \Delta \mathrm{Ct}} \cdot n=6-8$ in each group; each test was repeated three times. Data was expressed as mean $\pm \mathrm{SD}$. Analysis of differences among groups was conducted with one-way ANOVA-LSD. ${ }^{*} p<0.05$ and ${ }^{* * *} p<0.001$ versus NC; ${ }^{\#} p<0.05$ and ${ }^{\# \# \#} p<0.001$ versus CS.

suppressed and the balance became biased, leading to the development into AECOPD.

\section{Conclusions}

In summary, our study has successfully established a COPD murine model that showed features similar to clinical COPD. NTHi infection could induce AECOPD with lower lung function and more severe inflammation. Under the condition of cigarette smoke, we inferred an attenuating inflammatory effect of Tregs. When challenged with NTHi, an impairment of Treg function was found, however, accompanied with an enhancement of Th17 inflammatory responses. Our results supported the presence of a pro-/anti-inflammatory balance in COPD reflected by Th17/Treg cell responses. NHTi infection impaired the anti-inflammatory Treg balance, and an AECOPD developed.

\section{Conflicts of Interest}

The authors declare that they have no conflicts of interest.

\section{Authors' Contributions}

Xuewa Guan and Yanjiao Lu contributed equally to the work.

\section{Acknowledgments}

The project was supported by Jilin Provincial Science and Technology Planning Program (Grant no. 20150519015JH) and Jilin Department of Health (Grant no. 3D5172303426).

\section{References}

[1] L. Arcavi and N. L. Benowitz, "Cigarette smoking and infection," Archives of Internal Medicine, vol. 164, no. 20, pp. 2206-2216, 2004.
[2] L. Zuo, F. He, G. G. Sergakis et al., "Interrelated role of cigarette smoking, oxidative stress, and immune response in COPD and corresponding treatments," American Journal of Physiology-Lung Cellular and Molecular Physiology, vol. 307, no. 3, pp. L205-L218, 2014.

[3] J. K. Nikota and M. R. Stampfli, "Cigarette smoke-induced inflammation and respiratory host defense: insights from animal models," Pulmonary Pharmacology \& Therapeutics, vol. 25, no. 4, pp. 257-262, 2012.

[4] P. T. King and R. Sharma, "The lung immune response to Nontypeable Haemophilus influenzae (lung immunity to NTHi)," Journal of Immunology Research, vol. 2015, Article ID 706376, 14 pages, 2015.

[5] H. Janson, B. Carlén, A. Cervin et al., "Effects on the ciliated epithelium of protein D-producing and -nonproducing nontypeable Haemophilus influenzae in nasopharyngeal tissue cultures," Journal of Infectious Diseases, vol. 180, no. 3, pp. 737-746, 1999.

[6] Y. Kyo, K. Kato, Y. S. Park et al., "Antiinflammatory role of MUC1 mucin during infection with nontypeable Haemophilus influenzae," American Journal of Respiratory Cell and Molecular Biology, vol. 46, no. 2, pp. 149-156, 2012.

[7] S. Sethi, N. Evans, B. J. B. Grant, and T. F. Murphy, "New strains of bacteria and exacerbations of chronic obstructive pulmonary disease," The New England Journal of Medicine, vol. 347, no. 7, pp. 465-471, 2002.

[8] F. J. Alroqi and T. A. Chatila, "T regulatory cell biology in health and disease," Current Allergy and Asthma Reports, vol. 16, no. 4, p. 27, 2016.

[9] I. Shalev, H. Liu, C. Koscik et al., "Targeted deletion of $f g l 2$ leads to impaired regulatory $\mathrm{T}$ cell activity and development of autoimmune glomerulonephritis," Journal of Immunology, vol. 180, no. 1, pp. 249-260, 2008.

[10] J. Massague, “TGF $\beta$ signalling in context," Nature Reviews Molecular Cell Biology, vol. 13, no. 10, pp. 616-630, 2012.

[11] J. C. Mak, M. M. Chan-Yeung, S. P. Ho et al., "Elevated plasma TGF- $\beta_{1}$ levels in patients with chronic obstructive 
pulmonary disease," Respiratory Medicine, vol. 103, no. 7, pp. 1083-1089, 2009.

[12] N. Lane, R. A. Robins, J. Corne, and L. Fairclough, "Regulation in chronic obstructive pulmonary disease: the role of regulatory T-cells and Th17 cells," Clinical Science, vol. 119, no. 2, pp. 75-86, 2010.

[13] B. Barcelo, J. Pons, J. M. Ferrer, J. Sauleda, A. Fuster, and A. G. N. Agusti, "Phenotypic characterisation of Tlymphocytes in COPD: abnormal CD4+CD25+ regulatory T-lymphocyte response to tobacco smoking," The European Respiratory Journal, vol. 31, no. 3, pp. 555-562, 2008.

[14] H. Wang, H. Ying, S. Wang et al., "Imbalance of peripheral blood Th17 and Treg responses in patients with chronic obstructive pulmonary disease," The Clinical Respiratory Journal, vol. 9, no. 3, pp. 330-341, 2015.

[15] J. H. Rowe, J. M. Ertelt, M. N. Aguilera, M. A. Farrar, and S. S. Way, "Foxp $3^{+}$regulatory $\mathrm{T}$ cell expansion required for sustaining pregnancy compromises host defense against prenatal bacterial pathogens," Cell Host \& Microbe, vol. 10, no. 1, pp. 54-64, 2011.

[16] T. Hirano, S. Kodama, T. Kawano, and M. Suzuki, "Accumulation of regulatory $\mathrm{T}$ cells and chronic inflammation in the middle ear in a mouse model of chronic otitis media with effusion induced by combined eustachian tube blockage and nontypeable Haemophilus influenzae infection," Infection and Immunity, vol. 84, no. 1, pp. 356-364, 2015.

[17] J. R. McCann, S. N. Mason, R. L. Auten, J. W. St. Geme III, and P. C. Seed, "Early-life intranasal colonization with nontypeable Haemophilus influenzae exacerbates juvenile airway disease in mice," Infection and Immunity, vol. 84, no. 7, pp. 2022-2030, 2016.

[18] R. Vlahos and S. Bozinovski, "Recent advances in pre-clinical mouse models of COPD," Clinical Science, vol. 126, no. 4, pp. 253-265, 2014.

[19] K. K. Campos, R. G. Manso, E. G. Gonçalves et al., “Temporal analysis of oxidative effects on the pulmonary inflammatory response in mice exposed to cigarette smoke," Cellular Immunology, vol. 284, no. 1-2, pp. 29-36, 2013.

[20] J. L. Wright and A. Churg, "Animal models of cigarette smoke-induced chronic obstructive pulmonary disease," Expert Review of Respiratory Medicine, vol. 4, no. 6, pp. 723734, 2010.

[21] M. DuPage, A. L. Dooley, and T. Jacks, "Conditional mouse lung cancer models using adenoviral or lentiviral delivery of Cre recombinase," Nature Protocols, vol. 4, no. 7, pp. 10641072, 2009.

[22] J. A. Vanoirbeek, M. Rinaldi, V. De Vooght et al., "Noninvasive and invasive pulmonary function in mouse models of obstructive and restrictive respiratory diseases," American Journal of Respiratory Cell and Molecular Biology, vol. 42, no. 1, pp. 96-104, 2010.

[23] S. I. De Vleeschauwer, M. Rinaldi, V. De Vooght et al., "Repeated invasive lung function measurements in intubated mice: an approach for longitudinal lung research," Laboratory Animals, vol. 45, no. 2, pp. 81-89, 2011.

[24] L. Lüthje, T. Raupach, H. Michels et al., "Exercise intolerance and systemic manifestations of pulmonary emphysema in a mouse model," Respiratory Research, vol. 10, no. 1, p. 7, 2009.

[25] M. S. Dunnill, "Evaluation of a simple method of sampling the lung for quantitative histological analysis," Thorax, vol. 19, no. 5, pp. $443-448,1964$.
[26] J. Y. Sai, L. Xiong, J. Zheng et al., "Protective effect of Yinhua Miyanling tablet on lipopolysaccharide-induced inflammation through suppression of NLRP3/caspase-1 inflammasome in human peripheral blood mononuclear cells," Evidence-based Complementary and Alternative Medicine, vol. 2016, Article ID 2758140, 9 pages, 2016.

[27] A. Guerassimov, Y. Hoshino, Y. Takubo et al., “The development of emphysema in cigarette smoke-exposed mice is strain dependent," American Journal of Respiratory and Critical Care Medicine, vol. 170, no. 9, pp. 974-980, 2004.

[28] T. H. March, J. A. Wilder, D. C. Esparza et al., "Modulators of cigarette smoke-induced pulmonary emphysema in A/J mice," Toxicological Sciences, vol. 92, no. 2, pp. 545-559, 2006.

[29] M. J. Mammen and S. Sethi, "COPD and the microbiome," Respirology, vol. 21, no. 4, pp. 590-599, 2016.

[30] S. J. Moghaddam, C. E. Ochoa, S. Sethi, and B. F. Dickey, "Nontypeable Haemophilus influenzae in chronic obstructive pulmonary disease and lung cancer," International Journal of Chronic Obstructive Pulmonary Disease, vol. 6, pp. 113123, 2011.

[31] S. Ganesan, A. T. Comstock, B. Kinker, P. Mancuso, J. M. Beck, and U. S. Sajjan, "Combined exposure to cigarette smoke and nontypeable Haemophilus influenzae drives development of a COPD phenotype in mice," Respiratory Research, vol. 15, no. 1, p. 11, 2014.

[32] M. Bazett, A. Biala, R. D. Huff et al., "A novel microbe-based treatment that attenuates the inflammatory profile in a mouse model of allergic airway disease," Scientific Reports, vol. 6, no. 1, article 35338, 2016.

[33] M. Bazett, A. Biala, R. D. Huff et al., "Attenuating immune pathology using a microbial-based intervention in a mouse model of cigarette smoke-induced lung inflammation," Respiratory Research, vol. 18, no. 1, p. 92, 2017.

[34] A. N. Thorburn, P. S. Foster, P. G. Gibson, and P. M. Hansbro, "Components of Streptococcus pneumoniae suppress allergic airways disease and NKT cells by inducing regulatory T cells," Journal of Immunology, vol. 188, no. 9, pp. 4611-4620, 2012.

[35] A. N. Thorburn and P. M. Hansbro, "Harnessing regulatory T cells to suppress asthma: from potential to therapy," American Journal of Respiratory Cell and Molecular Biology, vol. 43, no. 5, pp. 511-519, 2010.

[36] E. Mortaz, I. M. Adcock, F. L. M. Ricciardolo et al., "Anti-inflammatory effects of Lactobacillus rahmnosus and Bifidobacterium breve on cigarette smoke activated human macrophages," PLoS One, vol. 10, no. 8, article e0136455, 2015.

[37] K. S. Smigiel, S. Srivastava, J. M. Stolley, and D. J. Campbell, "Regulatory T-cell homeostasis: steady-state maintenance and modulation during inflammation," Immunological Reviews, vol. 259, no. 1, pp. 40-59, 2014.

[38] H. Wang, L. Hou, D. Kwak et al., "Increasing regulatory T cells with interleukin-2 and interleukin-2 antibody complexes attenuates lung inflammation and heart failure progression," Hypertension, vol. 68, no. 1, pp. 114-122, 2016.

[39] W. Ouyang, J. K. Kolls, and Y. Zheng, "The biological functions of T helper 17 cell effector cytokines in inflammation," Immunity, vol. 28, no. 4, pp. 454-467, 2008.

[40] S. A. Khader, S. L. Gaffen, and J. K. Kolls, "Th17 cells at the crossroads of innate and adaptive immunity against infectious diseases at the mucosa," Mucosal Immunology, vol. 2, no. 5, pp. 403-411, 2009. 
[41] W. Chen and J. E. Konkel, "Development of thymic Foxp3 $3^{+}$ regulatory T cells: TGF- $\beta$ matters," European Journal of Immunology, vol. 45, no. 4, pp. 958-965, 2015.

[42] J. C. Zhang, G. Chen, L. Chen et al., “TGF- $\beta /$ BAMBI pathway dysfunction contributes to peripheral Th17/Treg imbalance in chronic obstructive pulmonary disease," Scientific Reports, vol. 6, no. 1, article 31911, 2016.

[43] M. P and J. K. Kolls, "Targeting IL-17 and $\mathrm{T}_{\mathrm{H}} 17$ cells in chronic inflammation," Nature Reviews Drug Discovery, vol. 11, no. 10, pp. 763-776, 2012.

[44] Y. Jin, Y. Wan, G. Chen et al., "Treg/IL-17 ratio and Treg differentiation in patients with COPD," PLoS One, vol. 9, no. 10, article e111044, 2014.

[45] A. O'Garra, B. Stockinger, and M. Veldhoen, "Differentiation of human $\mathrm{T}_{\mathrm{H}^{-}}-17$ cells does require TGF- $\beta$ !," Nature Immunology, vol. 9, no. 6, pp. 588-590, 2008.

[46] P. R. Mangan, L. E. Harrington, D. B. O'Quinn et al., "Transforming growth factor- $\beta$ induces development of the $\mathrm{T}_{\mathrm{H}} 17$ lineage," Nature, vol. 441, no. 7090, pp. 231-234, 2006. 


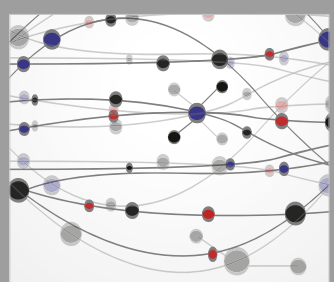

The Scientific World Journal
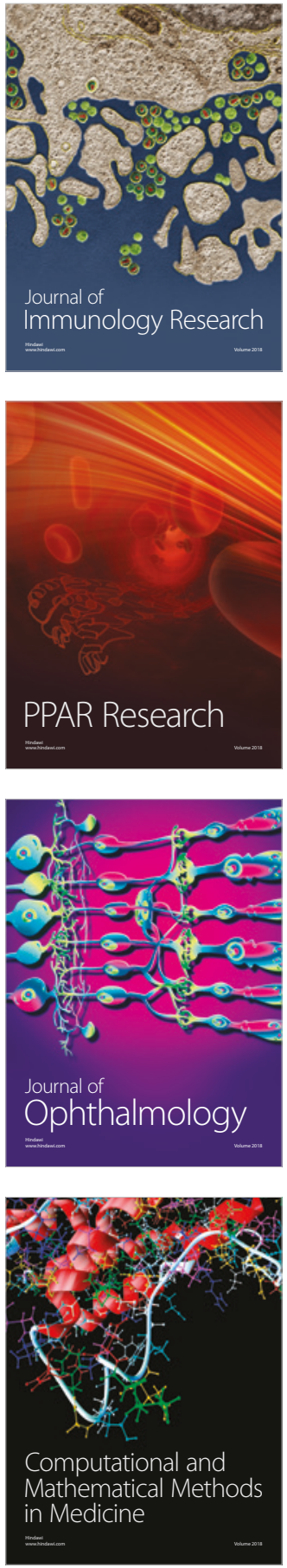

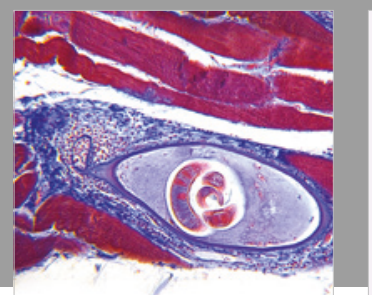

Gastroenterology Research and Practice

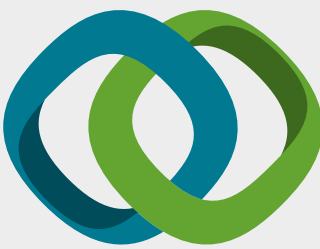

\section{Hindawi}

Submit your manuscripts at

www.hindawi.com
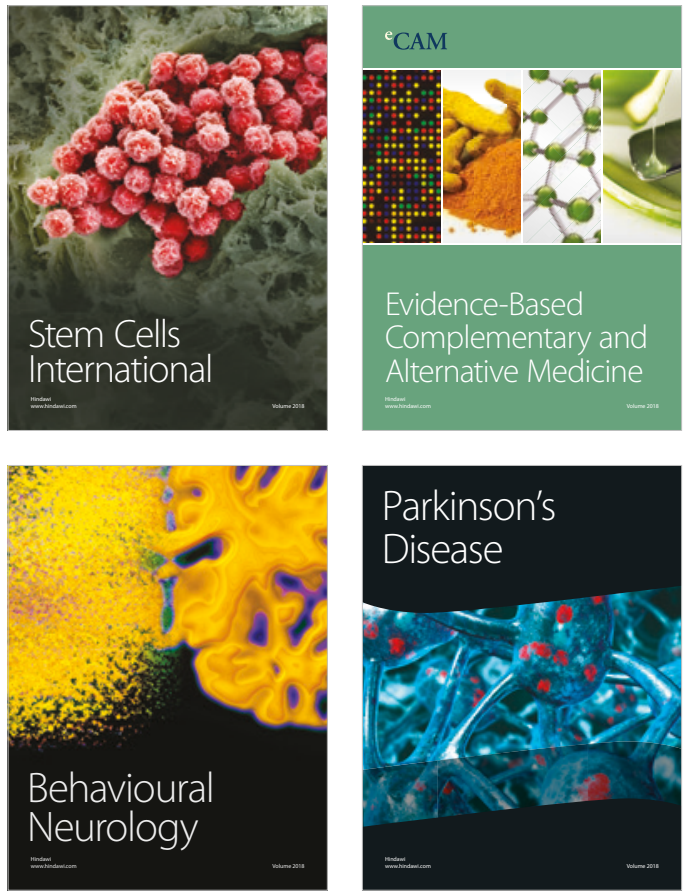

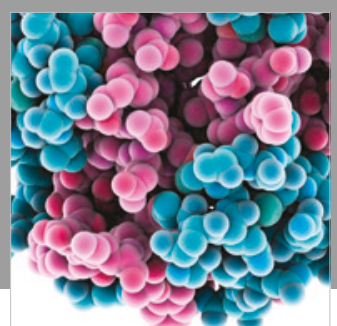

ournal of

Diabetes Research

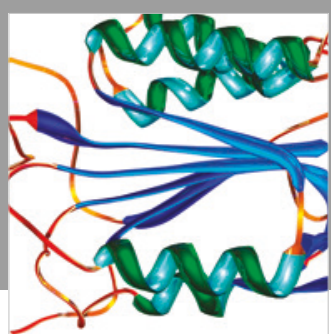

Disease Markers
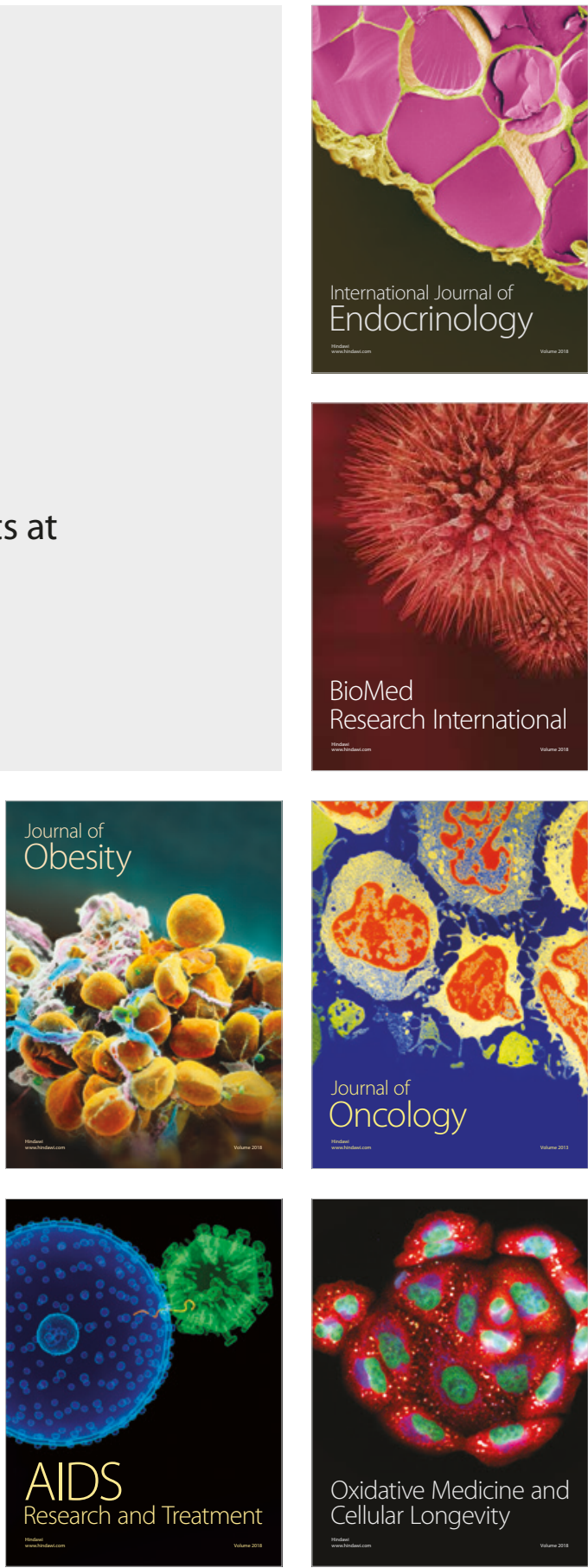